\title{
Correction to: Landfall After the Perfect Storm: Cohort Differences in the Relationship Between Debt and Risk of Heart Attack
}

\author{
Angela M. O'Rand ${ }^{1} \cdot$ Jenifer Hamil-Luker ${ }^{1}$ \\ Published online: 10 December 2020 \\ (C) Population Association of America 2020
}

\section{Correction to: Demography \\ https://doi.org/10.1007/s13524-020-00930-3}

The original version of the article was updated. Figure 2 was replaced with the correct version as below:

Angela M. O'Rand

aorand@duke.edu

Jenifer Hamil-Luker

jenifer.hamil@duke.edu

1 Department of Sociology, Duke University, 417 Chapel Drive, Durham, NC 27708-0088, USA 


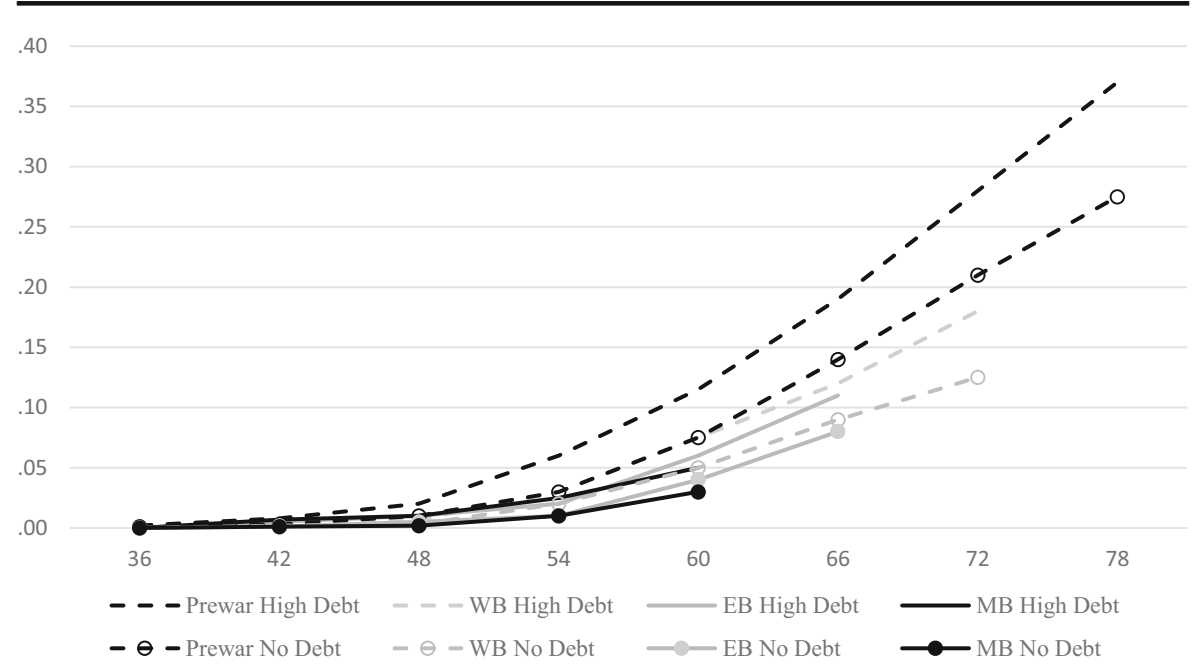

Fig. 2 Cumulative hazard of heart attack by age, cohort, and unsecured debt: Health and Retirement Study, 1992-2014. WB = War Baby, EB = Early Boomers, and MB = Mid-Boomers

Publisher's Note Springer Nature remains neutral with regard to jurisdictional claims in published maps and institutional affiliations. 